\title{
A Probe on Training of Primary Commanders' Leadership
}

\author{
Bai Yun, Jiang Dayong \\ College of Basic Military Education, Engineering University of PAP \\ wanghe717@163.com
}

\begin{abstract}
In view of the changes of combat style in the information age and the diversification of military missions, some new requirements have been put forward for the training of primary commander's leadership. How to meet the needs of transformation in the new era and cultivate more outstanding commanders is an urgent issue facing all military colleges, therefore, this paper, starts with the necessity of training the primary commander's leadership, proposes some training methods based on the discussion of elements needed by the primary commander's leadership.
\end{abstract}

Keywords-Primary commander; Leadership; Training; transformation

\section{INTRODUCTION}

With the impact of economic globalization and the advent of information age, the development of military high technology and the emergence of modern warfare with the characteristics of informatization, the armed forces of various countries in the world have gradually realized that a militant army has not only depend on advanced military theories, institutional preparation and weapons or equipment are far from enough. It must also strengthen the leadership training and change the model from "hard management" to "flexible leadership" and from experience to science [1]. New challenges were posed to the leadership of primary commanders. The colleges must face an issue that how to adjust to the needs in transition and to cultivate more outstanding primary commander with leadership. The paper starts with the necessity of training the primary commanders' leadership, and proposes some training method based on the elements of primary commanders ' leadership.

\section{NECESSITY OF TRAINING OF PRIMARY COMMANDERS' LEADERSHIP}

Foreign military researcher believes that "modern warfare is becoming a war decided by leadership". Beside of weapons confrontation, tactical competition and personnel competition, the commanders who lead the army decide the outcomes of war. The strength of leadership has a decisive influence on it. Therefore, it is very necessary to train leadership of primary commanders. First, the reform of combat methods in the information age has put forward higher requirements for the training of primary commanders' leadership. In the world, with the rapid development of high-tech with information technology as the main symbol and its wide application in the military field, profound changes in the form of war, military structure, weaponry, and combat theory have been triggered, which has promoted the degree of continuous improvement in military informationization. The operational style of modern warfare is joint operations under the guidance of information, with multiple strengths for participation in warfare, multiple dimensions in the battlefield, fierce command confrontation, and the effects of among battles, campaign and strategy. These changes require that primary commanders should own three capabilities including processing information, analysis and planning, and decision-making command, which are not all limited to their combat level.

Second, implementation of diversified military missions places higher demands on the training of primary commanders' leadership. With the development and changes in the international situation and in the face of global challenges such as terrorism, economic security, climate change, nuclear proliferation, information security, natural disasters, and public health security, the frequency of military operations has increased for various countries. Activities such as performances, anti-terrorism operations, and humanitarian aid have become an important way for the use of federal military forces. The ability and quality of primary commanders, especially leadership, is facing new challenges and plays an irreplaceable role in them. The diverse mission environment requires primary commanders to have good communication and coordination capabilities, strong proactive decision abilities, sophisticated regulatory and policy capabilities.

\section{ELEMENTS OF PRIMARY COMMANDERS' LEADERSHIP}

The primary commander leadership refers to the ability to accomplish organizational goals by influencing the behavior of others. It is a compound ability composed of multiple competencies. In order to cultivate the leadership, the elements must be realized. Combining with the needs of the current situation and the diversification of military mission, new connotations must be studied for primary commander leadership. In particular, the following eight aspects should be highlighted. 


\section{A. Insight}

Insight is the ability to see the nature of things. The diversification of military missions is characterized by rapid changes in the situation and a keen insight can ensure commanders to choose the right time to make predictions and use the situation. Therefore, the wide vision and forwardlooking thinking of commanders can distinguish complex situations, be good at tracing the essence of things, grasp the main aspects of contradictions and then rapidly make accurate judgments about the current situation, which were one of the major components of leadership.

\section{B. Strain}

The leadership of outstanding commanders often manifests itself in the decisive handling of complex emergencies. In particular, under the conditions of informatization, nonstylized characteristics of combat operations become more prominent. The "catastrophe" of war situations will become the norm in the course of operations. Therefore, the strain consciousness of primary commanders will be strengthened, and their thinking in dealing with emergencies will be cultivated. It is important for grasping the initiative of various military operations.

\section{Decision-making power}

The implementation of scientific decision-making is the most important responsibility of the leader. The strength of the leader's decision-making ability directly determines the performance of the leadership activity. This requires the leader to be good at independent thinking, grasp the crux of the actual contradiction and the opportunity of environmental space and time, and make decisions on various operational plans. Therefore, it is necessary to train primary commanders' agile thinking so that they can decisively determine their actions and take the most effective management of the organization under the complex circumstances.

\section{Charisma}

The effectiveness of leadership is largely determined by the opinions and attitudes of subordinates, and charisma is the foundation of these opinions and attitudes. Military officers with good charisma can receive the support of their subordinates and soldiers. They can strengthen the unity and coordination of their subordinates, and thus increase their morale and combat effectiveness. Therefore, it must be focused on cultivating the commander' pursuit of the influence of "non-power factors" and strive to shape the excellent quality of honesty, integrity, frankness, humility, and care in the course of practice. The finally aim makes them be the trusted commanders for their subordinates.

\section{E. Monitoring force}

Supervision and control are the leader's follow-up adjustment of the intention and implementation process of military operations. Its purpose is to better implement the operations of military mission. In the future, military operations will be able to command effectively because of the diversity of military forces, the wider operational area, the more fragmented combat units, the more complex battlefield situation, the complexity of information, and the incomprehensibility of information. As long as leaders have strong supervisory and control capabilities, they can command efficiently. Primary commanders must adapt to changes in the situation and misssion, and strive to improve organizational and coordination capabilities that meet needs of the diversified and multi-factor.

\section{F. Coordination}

Organizational coordination is indispensable for any military operation. It is also the most basic work way for commanders. In particular, in the process of diversifying military missions, there are multiple forces involved in the war, the command relationship is complex, and some are not affiliated with each other. As a temporary action group, the coordination among them is more difficult [2], because it not only includes intra-military coordination but also strengthens communication between the military and the localities, even involves international cooperation. The factors for coordination, scope, mission, and difficulty are far beyond the traditional military operations. Primary commanders must adapt to changes in the situation and missions, and strive to improve organizational and coordination capabilities that meet needs of diversified multi-factor.

\section{G. Communication}

The communication ability is a competency for leaders including vertical and horizontal communication. From a vertical perspective, commanders with strong communication skills can not only enable subordinates to accurately execute their own instructions, but also generate strong affinities and charisma to motivate subordinates to achieve greater results. From a horizontal perspective, with the increase in the number of international military cooperation missions and the rapid development of modern media technologies, it is particularly important to increase the ability of primary commanders to handle foreign affairs and communicate with the media.

\section{H. Innovation}

The ability to without sticking to conventions is part of the main pillars of leadership. The primary commander must have the will and passion to improve and innovate, and dare to overcome the resistance of the old habits. They should also be independent, courageous to go beyond conventional, critical, and multi-dimensional imagination. Finally, all action goals can be archived by innovating methods and approaches for leadership management. In addition, Primary commanders must also have the ability to creatively solve new situations and new problems so as to adapt to the intricate situation under the conditions of informatization. Only not sticking to 
one form and break the routine, they can deal with this situation effectively.

\section{TRAINING METHODS OF PRIMARY COMMANDERS' LEADERSHIP}

The training of primary commanders' leadership in the information age is a complex systematic project. It is another innovative project that is full of challenges. It requires colleges to carry out multi-level reform and innovation in all aspects of top-level design, teaching content, teaching methods, and training environment for institutional mechanisms.

\section{A. Top-level designs for leadership development}

The famous military academies all over the world have adopted the cultivation of outstanding leaders as its chiefly target. For example, West Point Military Academy of USA proposed to train the moral leaders; Royal Sandhurst Military Academy in the United Kingdom regards "serving in army as a leader" as its school motto [3]. Therefore, the most important mission for the development of leadership training is to determine leadership training goals and top-level design.

First of all, it is necessary to clear and definite ideas of the cultivate leaders, and always regard the training of primary commanders and leaders who meet the needs of the information age as the fundamental goal. Secondly, following the growth law of military leaders, starting with the eight types of leadership necessary for primary commanders, building a scientific system of leadership training model, formulating a systematic and standardized leadership training program, and developing a leadership training model. Various indicators should be resolved into teaching standards, extracurricular activities, management training criteria, and infiltration throughout the training. In addition, focusing on the training objectives of leadership, we must vigorously integrate education resources through establishing an integration philosophy and the goal of "everyone, always, everywhere" to serve future leaders. Only formulating a clear leadership development plan, then can ensure talents training points clear.

\section{B. Optimizing the structure and content of the curriculum system}

If Primary commanders want to own excellent leadership, they must possess rich knowledge of leadership and management. They should have a clear understanding of the psychological and behavioral laws of both leaders and subordinates, and have a correct judgment of the basic ethical norms so that properly handled or well-managed in the face of complex organizational and individual behavior. Therefore, in the course of teaching, we should increase the proportion of leadership management theory knowledge to enhance the students' theoretical ability. Main knowledge from five aspects needs to be strengthened:

First is the scientific knowledge of thinking. From the innovative, logical, systematic and other aspects of thinking, course in logic, philosophy, systems engineering should be set up to cultivate the ability to adapt to the need for leadership. The second is the knowledge of leadership which is the core of the curriculum. It is necessary to establish leadership science and leadership arts, military leadership, and other courses to enrich the theoretical knowledge of students in leadership and form a preliminary sense of leadership and quality. The third is modern management knowledge. In order to raise the level of leadership, we must learn the theory and methods of modern management science, master theoretical tools such as operations research, system theory and learning organization. Through using of modern management science theory, it can guide the work to improve planning, organization, decisionmaking, commanding, coordination and other basic abilities. The Fourth is psychological and behavioral science knowledge. Primary commanders are the main working objects of people. They must fully grasp the psychological and behavioral characteristics of their work subjects. They must learn basic human psychological characteristics through psychology, organizational behavior and ethics. The fifth is knowledge of force management. Based on the characteristics and requirements of the military, it should be set up military leadership management courses with obvious military characteristics and strong applicability to help trainees adapt to their job requirements, such as the establishment of various regulations for the army, so that trainees can understand common sense of the leadership of the army and ensure legal management.

\section{Building a platform for independent study and practical exercise}

To adapt to the needs of the education and teaching methods for primary commander in the information age, it must give priority to embodying students' subjectivity. Through mobilizing the students' learning initiative and increasing leadership effectiveness, we can gradually improve the students' memory of observation, inductive deduction, analysis of comprehensive power and judgmental decisionmaking power. In military training, it is necessary to highlight the key role of practice in capacity development, and actively explore and practice comprehensive drills, confrontation training, simulation training, military substitute training, field training, and military intensive training. At the same time, it makes great efforts to improve their ability of analyzing problems, scientific decision-making and organization and command ability.

In the field of non-course teaching, through the guidance of instructors and student-led methods, we organize and conduct a wide variety of group activities such as research competitions, sports clubs, and art festivals, so that the students clearly identify their positioning and responsibility in the participating of organizing activities. Then they can master the skills of communication and collaboration with others, improve self-confidence, self-discipline and willpower, and gradually develop the ability to teamwork, planning and coordination and accurate implementation. 


\section{Building a training environment that is close to the command position of troops}

In the generation process of leadership, the impact of environmental factors is very important. We must try our best to shorten the environmental differences between colleges and troops, and shorten the period of adaptation for the graduates in the new post. In the practice of trainee leadership training, it is necessary to fully create a realistic military training environment and simulate the management activities of the ministry (division) team to improve their familiarity with the army management positions. On the basis of achieving basic physical fitness and skills training standards, military training should also enrich the objectives of training students' military accomplishments, teamwork, and leadership management capabilities. Through extending the scope of field training, improving training standards and strength, trainees will have the overload pressure from physiological and psychological in a strange and difficult environment. It can hone their will quality, cultivate spirit of solidarity and mutual assistance, be bold in adventurous and enterprising, and be responsible for the team. Further, it can improve their ability to calmly think and judge correctly under complex environment. In addition, the enriching of experience for teachers and trainee team cadres in the colleges should be focused on. Teachers will be regularly selected to perform duties in the military, and outstanding military officers will be selected to serve in the colleges, so that it always maintains the orderly flow between colleges and military. It is necessary to build high-quality cultural teaching venues and facilities with military camp features that can meet the needs of teaching and training.

\section{E. Scientific inspections and training effects}

The effectiveness of leadership training must be tested by assessment. According to the object model by cultivating the leadership of the trainees, corresponding evaluation methods are formulated, and regular evaluations are conducted to test students' leadership training. It is necessary to concretely implement the assessment indicators to the details of student leadership behavior. The evaluation is carried out throughout the entire process of education and training so that the trainees are always observed and evaluated. Through information feedback, trainees can identify shortages and improve themselves in time. In addition, new forms of training can also be explored in such areas as the observation of joint military exercises, counter-terrorism exercises, and participation in peacekeeping operations, so as to expand the vision, experience, and ability of primary commanders.

\section{CONCLUSION}

Cultivation of primary commander leadership is a long and arduous mission. It is also significant. This article starts from the necessity and puts forward the method of training on the basis of the discussion of the constituent elements. It provides guidance and ideas for graduates to be competent for the first job.

\section{REFERENCES}

[1] WANG Junxia. Research on the cultivation of students' leadership ability in military university, Changsha: National University of Defense Technology, 2008.

[2] WANG Rui, LI Longmei, ZHOU Hao, ZHAO Wei. Analysis on the Training of Military Academy Students' Management Ability. The Journal of Higher Education, 2012, 3(02): 45-48.

[3] Yang Xiaodan. Energetically promote the talent strategy project - speed up the cultivation of new types of military personnel. Naval Academy Education. 2005, 15(02): 32-35. 